\title{
Death Valley Transportation
}

How the Borax is Transported from This Hottest of Regions to the Nearest Rail Connection

By John I. Von Blon

UNIQUE in the beginning, long ago, and so remaining to the present, transportation methods in Death Valley yet have undergone the processes of a most interesting evolution. most interesting evolution. particularly to the changes particularly to the changes
wrought in the hauling of wrought in the hauling of the output of the forbidding California sink's one great industry-borax production. Fifty, forty and as recent as twenty years since, the means of transport to the world without-for Death Valley was an infernal region apart-consisted of the "twenty-mule" teams that brought fame to themselves and the mysterious desert pit. The full story of the pomance and the tragedy romance and the tragedy that attended these indomi-
table commercial caravans table commercial caravans
through the hottest spot on through the hottest spot on
the globe never can be written. Swirling sands blotted it out from day to day. But these simple carriers made

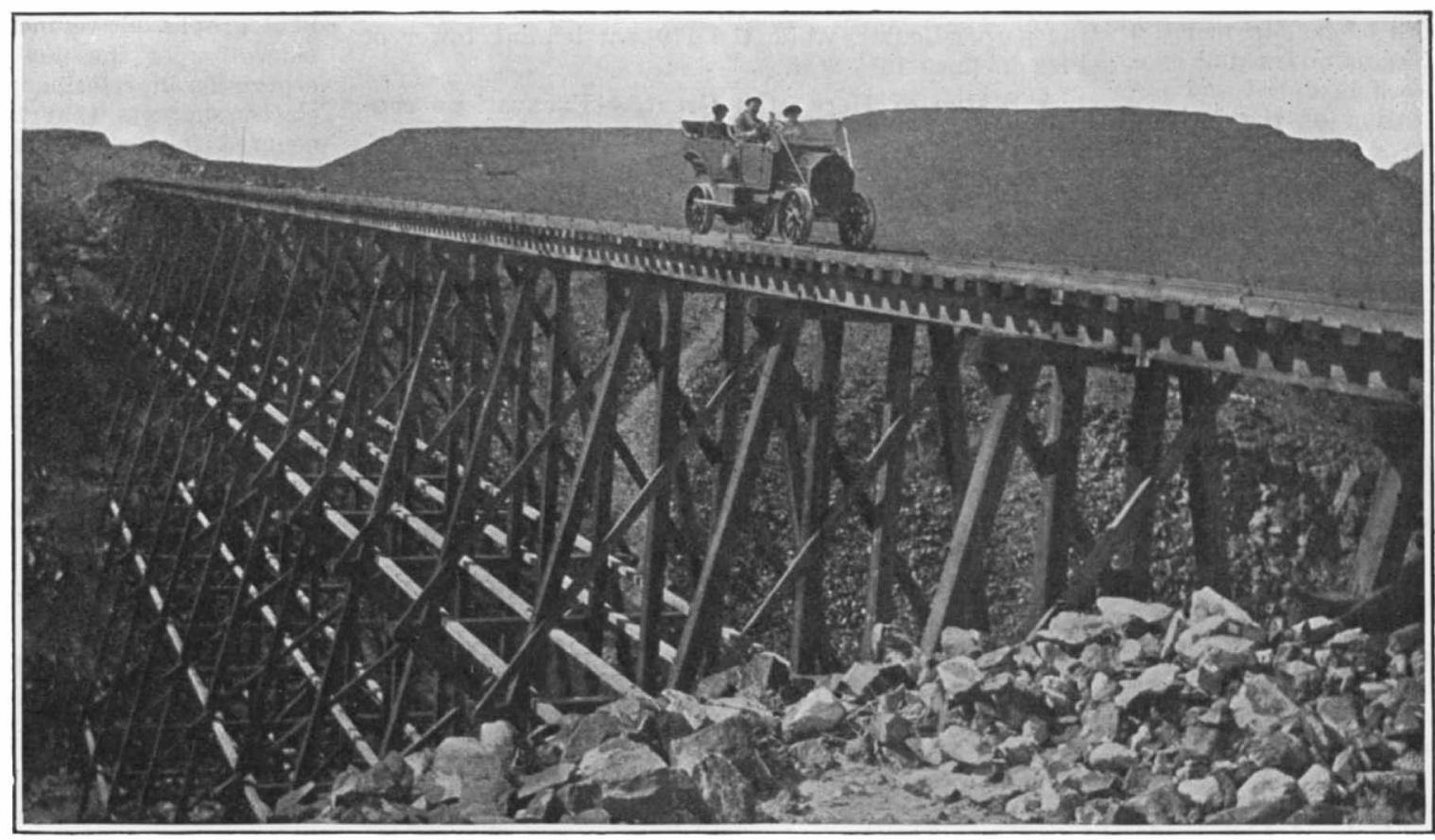

Automobile equipped with flanged wheels in daily operation, carrying mail and passengers, over the 20 miles of the Death Valley Railroad, between Ryan and the borax mines hours it would become so heated from the sun's intense rays that it had to be uncovered. Frequently it was pumped into the boiler practically at the steamproducing stage. Here probably is the one spot on the globe where it would be possible to install a steampower plant and operate it with little artificial heat. The temperature is furnacelike. Death Valley's maximum of 160 degrees Fahrenheit never has been equalled elsewhere. In the summer 140 is common, and at midnight the mercury hovers at 120 . So hat does the earth become in August that a rock or a bit of iron scorches the naked hand like a live coal. No wonder water boils in the sun! There was nothing pleasant about handling that tractor. Now the Death Valley railroad, itself a borax enterprise, reaches outside connections with mineral

good. The creaking wagons and the plodding mules clusively with sledge hammers. The action of heat proved themselves extraordinarily efficient in making and moisture from below had forced up salt pinnacles delivery many weary miles over burning alkali waste to hard as rock, two or three feet high and countless, and the nearest rail shipping point, and aided materially in these had to be hammered down. This road is unlike the making of a world civilization. If "cleanliness is any other. It facilitated hauling but it was cruel to next to godliness" they were a boon to humanity; for hoofs. Sloping down to this salt artery are several the cleansing agency they made available polished wide fields of crude borax-borate of soda. The main more than one continent. Still, the hardships, the and better deposits are higher up, which was a factor more than one continent. Stin, the hardships, the and better deposits are higher up, which was a factor downright misery suffered by beasts and drivers, are of consequence to the four-legged "locomotives." The beyond the comprehension of dwellers in blessed places "team" consisted of sixteen to twenty-two animals, de-
of brooks and shade and tempered breezes. As a rule pendent upon season and conditions. The leaders, it the animals lasted but a short time. A large propor- will be observed by reference to the illustration, were tion of the teamsters, however, once inured to the horses. This was because these proved steadier and life, jogged forth and back through the blinding white more intelligent in responding to the directions jerked dust for years and years, and for most of them it be- from the driver's seat at the rear of the long dustcame a shroud after the race was run. To live in laden column.

came a shrile in the weird silence, gray and sombre, between the Pane "desert rat" does not leave because he-cannot be con-
tent elsewhere. A few of the old-time drivers survive. The climate has the virtue of being exceedingly healthful for those who can stand it.

The tugging strings of mule flesh drew their unwieldy loads on wretched trails, ever changing-the deep gashes cut in hideous hills by cloudburst, the rough wash and the treacherous salt marsh, where bottom is an uncertainty. In one place more than thirty years ago an eight-mile stretch of road six feet wide was built across a solid reach of salt and graded ex- trains, linking the principal mines with the station of
Ryan. This is a trackage of twenty miles and here Ryan. This is a trackage of twenty miles and here
again an unusual vehicle is in operation. This is an old automobile equipped with flanged wheels and it carries the mail daily between the two points, handling also occasional passengers and making surprisingly good time. Because of frequent violent gales, hot as blasts of flame, a stop is out of the question but riding is made tolerable by speeding up. Sometimes on a trestle a whiff of cool air is encountered. Occasionally the machine is blown off the rails.

At the mines, where the landscape ever looks like a snowfield but doesn't feel at all that way, gasoline motors are employed for borax and other hauling.

When progress demanded more expeditious service mules were superseded by steam, a slow but sure heavy tractor of the upright type drawing laden trailers to railhead. The Piute Indians, Arabs of Inyo, called this contrivance "fire devil" and for months they wouldn't venture within a hundred yards of the smoking, hissing monster. In the more torrid season the crews suffered terribly, and a man on one of the wagons died with a canteen of water in his hand. The accompanying photograph was taken in the winter, when ice frequently forms. In front of the boiler a cold-water tank was ingeniously anchored on the tractor. The water in it never was long cold. In a few

\section{The Temperature at Which Fish Thrive}

E XPERIMENTS recently made abroad by M. P. of the fish. In the case of those qsh which are classified as enrythermic when subjected to a constant temperature of 14 or $15 \mathrm{deg}$. Cent., they do not grow as well as the parent fish which have been subjected to the ordinary seasonal variations of temperature But when the offspring are kept at a constant temperature of 20 or $21 \mathrm{deg}$. Cent., on the other hand, they grow much faster, and faster still at 24 or $25 \mathrm{deg}$. Cent., so that by the time they have reached their fourth year they are twice as large as fish living naturally. show that this varies markedly according to the nature

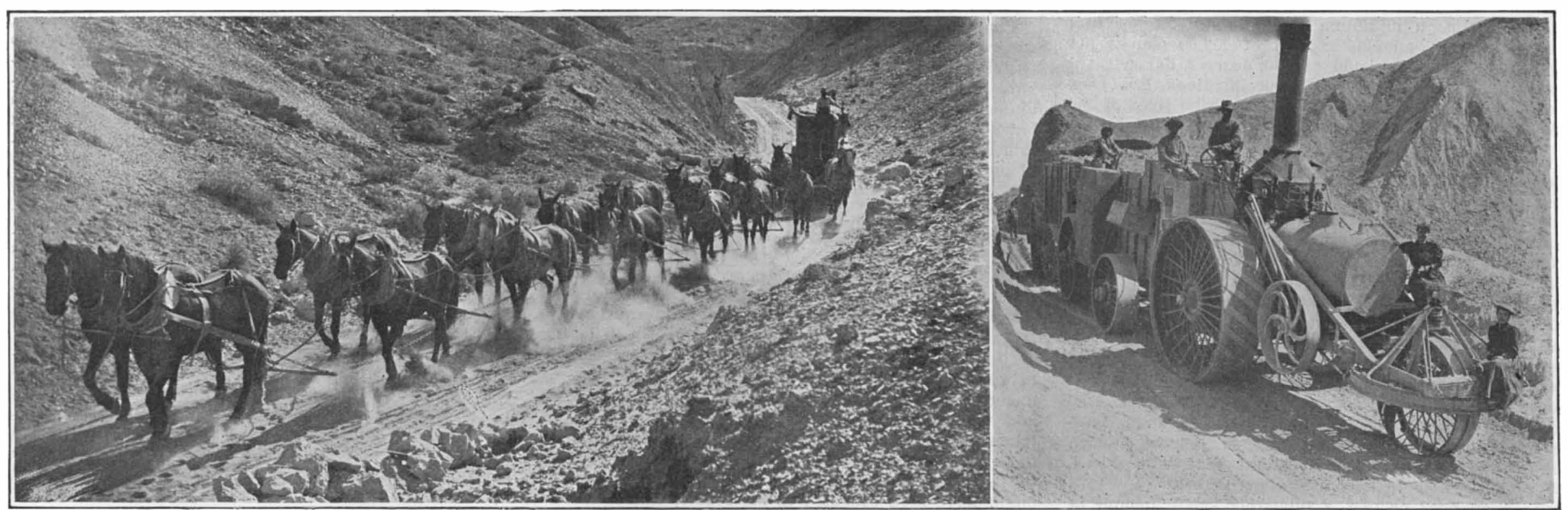

Left: 'The famous "twenty-mule" team of twenty years ago. Right: This steam tractor train superseded the mule wagons. Note the improvised water tank ingeniously anchored in front of the boiler 